\title{
Rapid Determination of Saponification Value and Polymer Content of Vegetable and Fish Oils by Terahertz Spectroscopy
}

\author{
Feng Ling Jiang ${ }^{1}$, Ikuo Ikeda ${ }^{1}$, Yuichi Ogawa ${ }^{2}$ and Yasushi Endo ${ }^{3 *}$ \\ ${ }^{1}$ Graduate School of Agricultural Science, Tohoku University (Sendai 981-8555, Japan) \\ ${ }^{2}$ Graduate School of Agriculture, Kyoto University (Kyoto 606-8502, Japan) \\ ${ }^{3}$ School of Bioscience and Biotechnology, Tokyo University of Technology (Tokyo 192-0982, Japan)
}

\begin{abstract}
A rapid method for determining the saponification value (SV) and polymer content of vegetable and fish oils using the terahertz ( $\mathrm{THz}$ ) spectroscopy was developed. When the $\mathrm{THz}$ absorption spectra for vegetable and fish oils were measured in the range of 20 to $400 \mathrm{~cm}^{-1}$, two peaks were seen at 77 and $328 \mathrm{~cm}^{-1}$. The level of absorbance at $77 \mathrm{~cm}^{-1}$ correlated well with the SV. When the THz absorption spectra of thermally treated high-oleic safflower oils were measured, the absorbance increased with heating time. The polymer content in thermally treated oil correlated with the absorbance at $77 \mathrm{~cm}^{-1}$. These results demonstrate that the $\mathrm{THz}$ spectrometry is a suitable non-destructive technique for the rapid determination of the $\mathrm{SV}$ and polymer content of vegetable and fish oils.
\end{abstract}

Key words: vegetable oil, fish oil, saponification value, polymer content, terahertz spectroscopy

\section{Introduction}

Determination of the saponification value (SV) of fats and oils is extremely important for estimating their degree of average molecular weights. SV determination is especially necessary for defining the quality of fish oils, because their fatty acid composition of fish oils varies with fishing season and area, and some fish oils may include not only triacylglycerol (TAG) but also wax ester or diacyl glyceryl ether (DAGE). Titration is generally used as the official method ${ }^{1)}$ for determining the SV of fats and oils, but it is difficult to obtain reliable results because highly skilled analysts are required to perform the titration and the conventional method takes more than $1 \mathrm{~h}$ to complete the analysis of a sample. The SV of vegetable oil can be calculated from the fatty acid composition estimated by gas liquid chromatography (GLC). However, the GLC method is time consuming and requires methylation pretreatment.

As polymers are formed during deep-frying with vegetable oils, the level of deterioration of the oil can be estimated by determining its polymer content. High-performance liquid chromatography (HPLC) is often used to determine the polymer content in fats and oils ${ }^{2}$, but it requires the use of organic solvents such as tetrahydrofuran.
Recently, near-infrared (NIR) spectroscopy has become an accepted method for the determination of the quality of fats and oils because it does not require toxic organic solvents and because it is a rapid technique. Some researchers have applied the NIR spectroscopy for determining the values of free fatty acids ${ }^{3,4)}$ and peroxide values ${ }^{5,6)}$ of edible fats and oils. The McGill University IR Group ${ }^{7,8)}$ developed the NIR method for determining the SV and iodine value (IV) of vegetable oils. In a previous study, we applied the NIR spectrometry to fish oils in the range of 2000 to $12000 \mathrm{~cm}^{-1}$ to determine their SV and $\mathrm{IV}^{9)}$.

Our group has developed the terahertz $(\mathrm{THz})$ spectrometry that enables the monitoring of the region between 10 and $400 \mathrm{~cm}^{-1}$, and that can be applied to food components such as sugars ${ }^{10)}$ and drugs ${ }^{11-13)}$. In a previous study ${ }^{14)}$, we also applied the THz spectroscopy to fatty acids and their analogues, and we found that all fatty acids had the same absorption peaks but the carboxylic group or the ester bond affected the spectra.

In this paper, we report the application of the $\mathrm{THz}$ method for determining the SV and polymer content of vegetable and fish oils, and then we discuss the efficiency of THz method for analyzing fats and oils.

\footnotetext{
Tokyo 192-0982, Japan

E-mail: endo@bs.teu.ac.jp

Accepted May 15, 2012 (recieved for review March 13, 2012)

Journal of Oleo Science ISSN 1345-8957 print / ISSN 1347-3352 online

http://www.jstage.jst.go.jp/browse/jos/ http://mc.manusriptcentral.com/jjocs
}

*Correspondence to: Yasushi Endo, School of Bioscience and Biotechnology, Tokyo University of Technology, 


\section{Materials and Methods}

\subsection{Vegetable and fish oils}

Refined coconut, corn, linseed, palm kernel, rapeseed, soybean and high-oleic safflower oils were provided by Nisshin OilliO Group, Ltd. (Tokyo, Japan). Refined rosy soldier, sardine, squid liver, and tuna oils were provided by Nippon Suisan Kaisha, Ltd. (Tokyo, Japan). Shark liver oil was provided by NOF Corp. (Tokyo, Japan). All vegetable and fish oils were of commercial grade.

\subsection{Measurement of $\mathrm{SV}^{1)}$}

The titration method to determine SV in fish oils and the "Standard Methods for the Analysis of Fats, Oils and Related Materials" published by The Japan Oil Chemists' Society $(1996)^{1)}$ were employed.

\subsection{Measurement of polymer content ${ }^{2)}$}

Thermally treated high-oleic safflower oils were dissolved in tetrahydrofuran $(5 \mathrm{mg} / \mathrm{mL})$ and a $25 \mu \mathrm{L}$ sample was injected into the HPLC. For HPLC analysis, two gel-filtration columns, Shodex GPC KF-8025 (300 mm $\times 8$ mm i.d) were used as columns. Polymers were eluted with tetrahydrofuran as a mobile phase at a flow rate of $1.0 \mathrm{~mL} / \mathrm{min}$ at $40^{\circ} \mathrm{C}$, and they were monitored with a refractive index detector.

\subsection{Terahertz spectroscopy}

A Fourier transform-infrared (FT-IR) spectrophotometer (JASCO Corp. Tokyo, Japan)was remodeled using a silicon broadband beam splitter and a deuterated L-alanine-doped triglycine sulfate (DLATGS) room-temperature detector, to obtain spectra in the range of 20 to $400 \mathrm{~cm}^{-1}$. The light source was a high-pressure mercury lamp, which has a higher intensity than a ceramic lamp below $3 \mathrm{THz}$.

Vegetable and fish oils were dissolved in liquid paraffin at a concentration of $5 \%(\mathrm{w} / \mathrm{w})$, and were placed in a polyethylene cell with a $1.0 \mathrm{~mm}$ path length and a volume of 1.0 $\mathrm{mL}$. The polyethylene cell and liquid paraffin are well suited for THz spectrometry, as they have no notable absorption at 20 to $400 \mathrm{~cm}^{-1}$. As a room-temperature reference, the $\mathrm{THz}$ absorption spectrum of the polyethylene cell was measured before the collection of the data for the fats and oils. The wavenumber resolution was $16 \mathrm{~cm}^{-1}$ and the

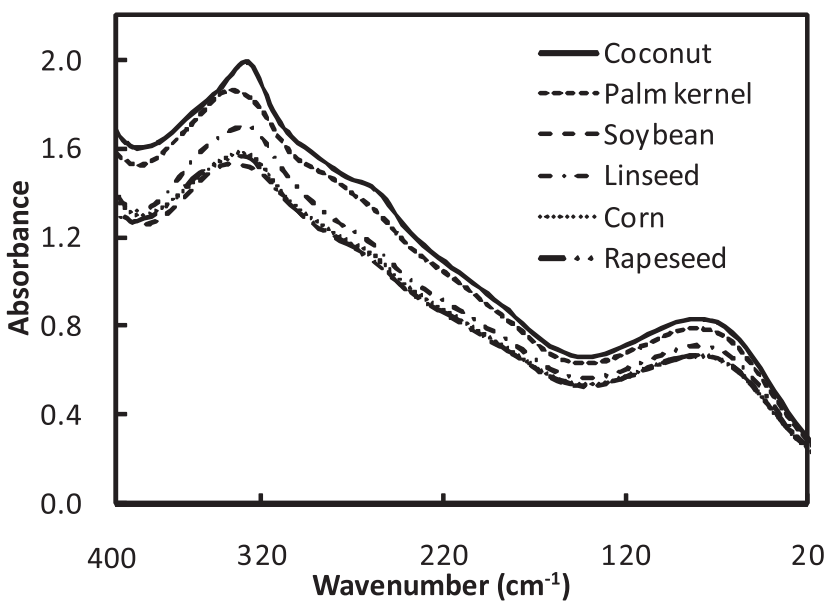

Fig. 1 The THz absorption spectra of vegetable oils.

accumulation was 128 times. The data represent the average of triplicate measurements.

\section{Results and Discussion}

\subsection{Vegetable oil}

Figure 1 shows the THz absorption spectra of coconut, corn, linseed, palm kernel, soybean and rapeseed oils as typical vegetable oils in the range of 20 to $400 \mathrm{~cm}^{-1}$. All $\mathrm{THz}$ spectra were similar in spite of the different fatty acid compositions. Notable absorption peaks were found at 77 and $328 \mathrm{~cm}^{-1}$, which may be due to the fatty acid, mainly the "-COO-". These peaks were also observed for free fatty acid, but the absorption peak at $231 \mathrm{~cm}^{-1}$ detected in free fatty acids was not found in the spectra of the vegetable oils. Moreover, no peaks were found for aldehyde and ketone. The absorbance was seen to depend on depended on the type of vegetable oils. Among six vegetable oils that were tested, coconut oil had the highest absorbance, followed by palm kernel oil, linseed oil, and soybean, corn, and rapeseed oils. Table 1 shows the SV of vegetable oils, which were in the range of 182 to 252 . The SV of coconut oil was 252 and the highest among 6 vegetable oils, whereas that of rapeseed oil was the lowest. These results suggest that the SV of vegetable oils could be related to the

Table 1 Saponification value of vegetable and fish oils.

\begin{tabular}{lclc}
\hline \multicolumn{1}{c}{ Vegetable oil } & Saponification value & \multicolumn{1}{c}{ Fish oil } & Saponification value \\
\hline Coconut & 252 & Tuna & 191 \\
Palm kernel & 241 & Sardine & 183 \\
Soybean & 190 & Squid liver & 176 \\
Linseed & 189 & Rosy soldier & 113 \\
Corn & 189 & Shark liver & 20 \\
Rapeseed & 182 & & \\
\hline
\end{tabular}


absorbance in the $\mathrm{THz}$ region.

A correlation curve was made to demonstrate the relationship between the SV and the absorbance at $77 \mathrm{~cm}^{-1}$. The value at $77 \mathrm{~cm}^{-1}$ was used as it could be derived from the "-COO-" in glyceride but not in methyl or ethyl esters, and the absorbance at $328 \mathrm{~cm}^{-1}$ could be markedly affected by the presence of moisture ${ }^{14)}$. As shown in Fig. 2, a good linear relationship $(R=0.969)$ was obtained between the SV and the absorbance.

\subsection{Fish oil}

Figure 3 shows the $\mathrm{THz}$ spectra of rosy soldier, sardine, shark liver, squid liver, and tuna oils as fish oils. All fish oils had the similar spectra in the range of 20 to $400 \mathrm{~cm}^{-1}$, except for squid liver oil. They had notable absorption peaks at 77 and $328 \mathrm{~cm}^{-1}$, and their spectral patterns were the same as those of the analyzed vegetable oils. These peaks may be also due to the "-COO-”. Squid liver oil had

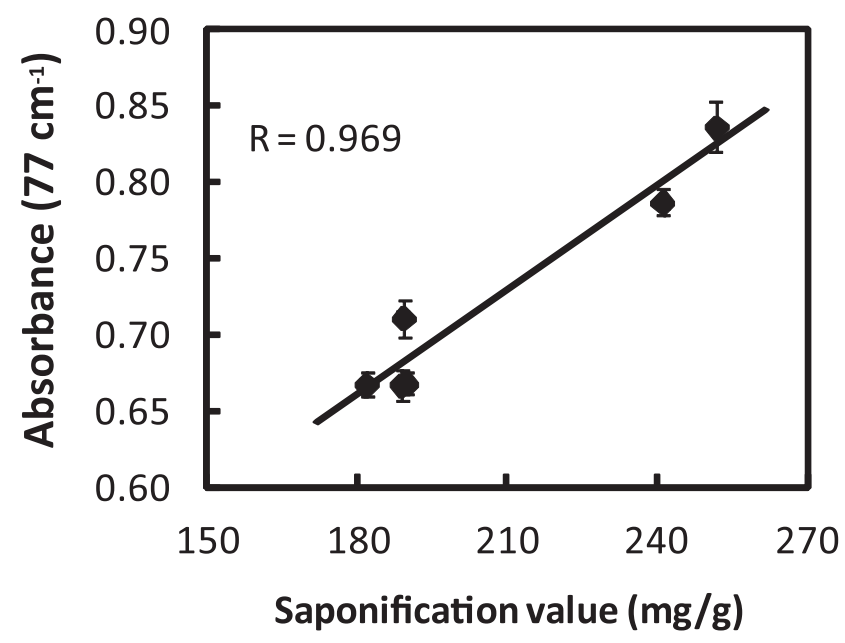

Fig. 2 Plot of saponification value against THz absorbance at $77 \mathrm{~cm}^{-1}$ of vegetable oils.

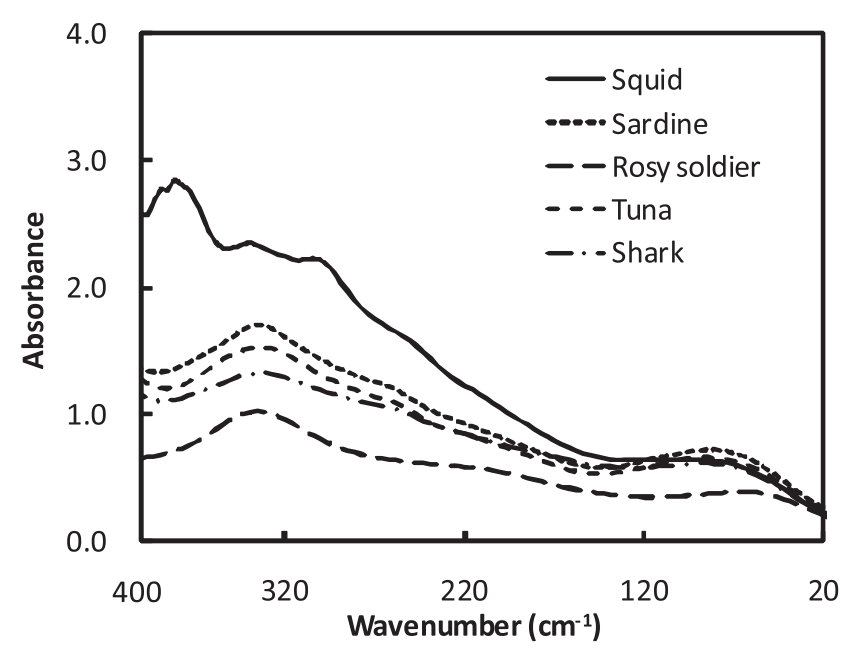

Fig. 3 The THz absorption spectra of fish oils. the highest absorption peak at $380 \mathrm{~cm}^{-1}$. The intense red color of squid liver oil, due to its high vitamin A content might affect the $\mathrm{THz}$ absorption spectrum. The absorbance of fish oils also depended on the varieties. Squid liver oil had the highest absorbance among five fish oils that were tested, whereas rosy soldier oil had the lowest absorbance.

Table 1 shows the SV of the different fish oils. Fish oils cover a broad range SV(20-191). Among the five fish oils, the SV of sardine oil was the highest at 191, whereas rosy soldier oil had a lower SV(113). Rosy soldier oil had so much wax esters that the SV was lower than TAG-rich oil such as sardine or tuna oil. Shark liver oil had the lowest SV (20) among all fish and vegetable oils tested, as its main components are hydrocarbons. The effects of unsaponifiable components such as tocopherols and phytosterols on the $\mathrm{THz}$ absorbance of fats and oils were investigated. At concentrations below $1 \mathrm{wt} \%$, they were seen to have no effect on the $\mathrm{THz}$ absorbance over the range of 20 to 400 $\mathrm{cm}^{-1}$ at the concentration below $1 \mathrm{wt} \%$ (data not shown).

Therefore, a correlation curve was made for fish oils between the SV and the absorbance at $77 \mathrm{~cm}^{-1}$ for the fish oils produced. As shown in Fig. 4, a good linear relation$\operatorname{ship}(R=0.962)$ was also obtained for the fish oils.

These observations suggest that the absorbance at 77 $\mathrm{cm}^{-1}$ derived from the ester bond in vegetable and fish oils may follow the law of Lambert-Beer low.

\subsection{Thermally treated oil}

High-oleic safflower oil(800 g) was heated in a deep-frying pan at $180^{\circ} \mathrm{C}$ with spraying water for different durations up to $50 \mathrm{~h}$, to prepare the thermally treated oil model. The high-oleic safflower oil was polymerized during heating, and the polymer content was found to be $15,27,36,52$, and $48 \%$ for $10,20,30,40$ and $50 \mathrm{~h}$ of heating time, respectively. Figure 5 shows the THz spectra of thermally

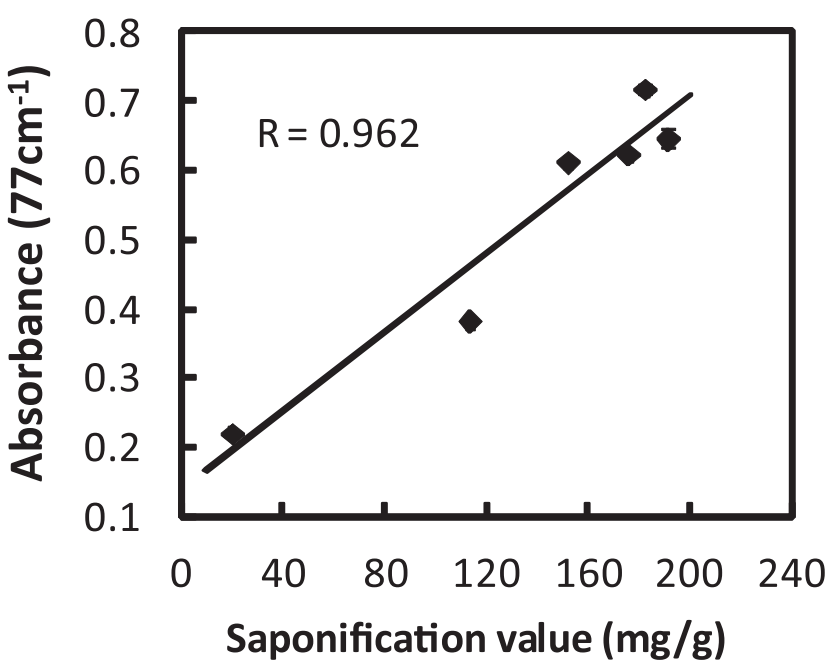

Fig. 4 Plot of saponification value against $\mathrm{THz}$ absorbance at $77 \mathrm{~cm}^{-1}$ of vegetable oils. 


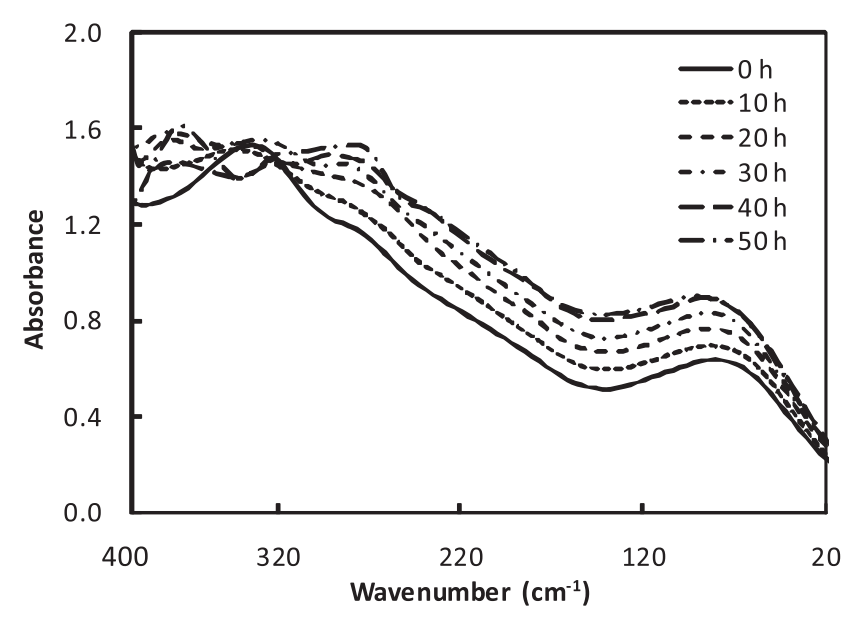

Fig. 5 The THz spectra of high-oleic safflower oils heated for $10,20,30,40$ and $50 \mathrm{~h}$ at $180^{\circ} \mathrm{C}$.

treated oils, all showing similar patterns over the range of 20 to $400 \mathrm{~cm}^{-1}$ in spite of the different degrees of deterioration. All thermally treated oils and the fresh oils had notable absorption peaks at $77 \mathrm{~cm}^{-1}$. However, the absorbance of thermally treated oils depended on the deterioration degree. The THz absorbance of high-oleic safflower oil increased with heating time.

A correlation curve showing the relationship between polymer content and absorbance at $77 \mathrm{~cm}^{-1}$ demonstrated an excellent linear relationship for the thermally treated oils (Fig. 6). The coefficient of determination was 0.990 . This good correlation between $\mathrm{THz}$ absorbance and polymer content of thermally treated oil was also observed for corn oil (data not shown). It is known that the polymer-

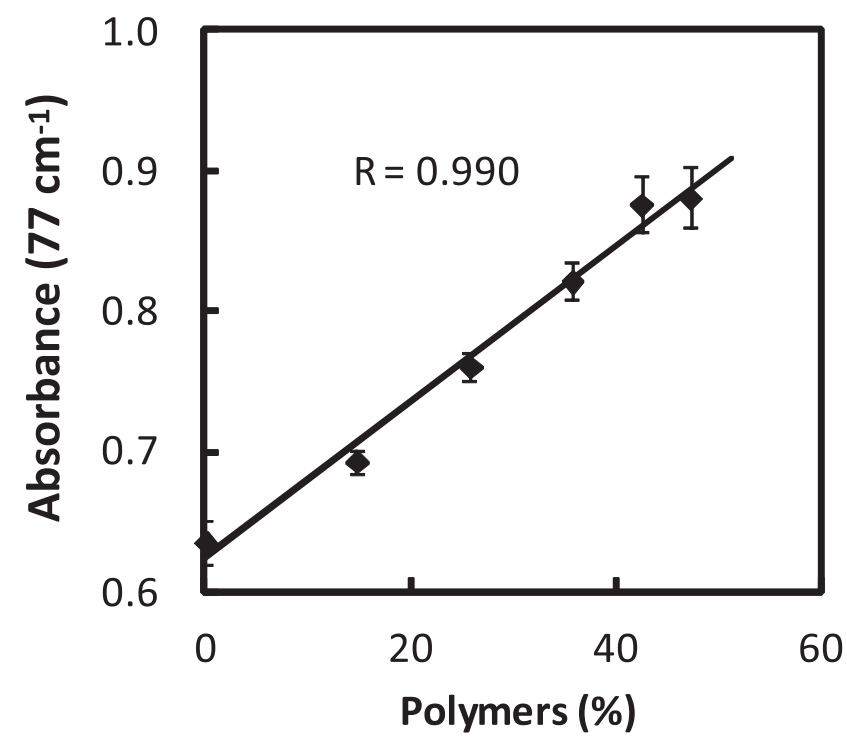

Fig. 6 Plot of polymer content against the THz absorbance at $77 \mathrm{~cm}^{-1}$ of high-oleic safflower oils heated at $180^{\circ} \mathrm{C}$. ization of edible oils during deep-frying of edible oils may increase the $\mathrm{SV}^{21)}$, and in this work, the SV of thermally treated high-oleic safflower oil increased with heating time (data not shown). The polymerization and thermal oxidation may apparently enhance the $\mathrm{THz}$ absorbance of "-COO-", although the presence of free fatty acids corresponding to acid value 3 formed by hydrolysis of TAGs did not affect the THz absorbance. The peak at $231 \mathrm{~cm}^{-1}$ due to free fatty acids was not found in the thermally treated oils. These results demonstrate that $\mathrm{THz}$ absorption spectrometry could be an effective technique for evaluating the quality of thermally treated oil.

It is well known that the NIR technique using the partial least squares (PLS)algorithm is effective for determining the chemical characteristics of edible oils ${ }^{7-9)}$. NIR analysis takes approximately 2 min per sample, making it much faster than the titration method. Moreover, the NIR technique does not require the use of harmful solvents.

$\mathrm{THz}$ spectroscopy is another non-destructive analytical method that needs no organic solvent. Thus, many researchers in the field of biophysics and biochemistry have adopted THz spectroscopy. There have been some reports concerning the $\mathrm{THz}$ absorption spectra of biomolecule and food component such as carbohydrates, amino acids, polypeptides, and vitamins ${ }^{15-20)}$. However, there are few reports for fats and oils. Hu et al. ${ }^{22)}$ observed that vegetable oils had broad peaks at 0.2 to $1.6 \mathrm{THz}\left(7\right.$ to $53 \mathrm{~cm}^{-1}$ ), although the THz region between 100 and $400 \mathrm{~cm}^{-1}$ was not measured for fats and oils. We observed $\mathrm{THz}$ absorption peaks for fats and oils at 77 and $328 \mathrm{~cm}^{-1}$. Moreover, $\mathrm{THz}$ absorption spectra have not been discussed in relation to the chemical characteristics of fats and oils. In this paper, we demonstrated that the level of $\mathrm{THz}$ absorbance of edible oils at $77 \mathrm{~cm}^{-1}$ correlated with the SV. In previous work ${ }^{14)}$, we found that the THz spectral pattern of saturated fatty acids differed from those of unsaturated fatty acids, which suggested that the crystalline structure of fatty acids may affect the $\mathrm{THz}$ absorption spectra. In the future, we will investigate the relationship between the $\mathrm{THz}$ absorption spectrum and steric structure of fats and oils including TAGs.

\section{Conclusions}

A THz spectroscopy technique was applied for the determination of SV and polymer content of vegetable and fish oils. The THz absorption spectra were independent of the variety of vegetable and fish oils in the range of 20 to 400 $\mathrm{cm}^{-1}$. However, the $\mathrm{THz}$ absorbance was well correlated with the SV of vegetable and fish oils. When THz spectrometry was applied to thermally treated oils, the THz absorbance was increased with polymer content in the oil. THz method is useful for SV and polymer content determination 
in edible oil, as it does not need harmful organic solvent and the measurement time is only 2-3 min per sample.

\section{References}

1) The Japan Oil Chemists' Society (1996) Saponification value: 2.3.2.1-1996, "Standard Methods for the Analysis of Fats, Oils, and Related Materials". JOCS.

2) The Japan Oil Chemists' Society (2005) Polymers content: Tentative 16-2005, "Standard Methods for the Analysis of Fats, Oils, and Related Materials". JOCS.

3) Ismail, A. A.; van de Voort, F. R.; Emo, G.; Sedman, J. Rapid quantitative determination of free fatty acids in fats and oils by Fourier transform infrared spectroscopy, J. Am. Oil Chem. Soc. 70, 335-341 (1993).

4) Man, Y. B. C.; Moh, M.H. Determination of free fatty acids in palm oil by near-infrared reflectance spectroscopy. J. Am. Oil Chem. Soc. 75, 557-562 (1998).

5) Hong, J.; Yamaoka-Koseki, S.; Yasumoto, K. Analysis of peroxide values in edible oil by near-infrared spectroscopy. Nippon Shokuhin Kogyo Gakkaishi 41, 277 280 (1994).

6) Moh, M. H.; Man, Y. B. C.; van de Voort, F. R; Abdullah, W. J. W. Determination of peroxide value in thermally oxidized crude palm oil by near-infrared spectroscopy. J. Am. Oil Chem. Soc. 76, 19-23(1999).

7) Li, H.; van de Voort, F. R.; Sedman, J.; Ismail, A. A. Rapid determination of cis and trans content, iodine value, and saponification number of edible oils by Fourier transform near-infrared spectroscopy. J. Am. Oil Chem. Soc. 76, 491-497 (1999).

8) Li, H.; van de Voort, F. R.; Ismail, A. A.; Sedman, J.; Cox, R.; Simard, C.; Buijs, H. Discrimination of edible oil products and quantitative determination of their iodine value by Fourier transform near-infrared spectroscopy. J. Am. Oil Chem. Soc. 77, 29-36 (2000).

9) Endo, Y.; Tagiri-Endo, M.; Kimura, K. Rapid determination of iodine value and saponification value of fish oils by near-infrared spectroscopy. J. Food Sci. 70, 127-131 (2005).

10) Abe, K.; Hayashi, S.; Doki, N.; Otani, C.; Kawase, K.; Miyazawa, T.; Ogawa, Y. Measurement of hydrated water in d-glucose powder using THz-wave spectroscopy, BUNSEKI KAGAKU 56, 851-856 (2007).
11) Kawase, K.; Ogawa, Y.; Watanabe, Y.; Inoue, H. Nondestructive terahertz imaging of illicit drugs using spectral fingerprints. Optics Express 11, 2549-2554 (2003).

12) Kawase, K.; Watanabe, Y.; Ogawa, Y.; Ito, H. Component spatial pattern analysis of chemicals using terahertz spectroscopic imaging. IEEJ Trans EIS 124, 1339-1344 (2004).

13) Ogawa, Y. Application of terahertz imaging to analysis. BUNSEKI 2007, 575-578(2007).

14) Jiang, F. L.; Ikeda, I.; Ogawa, Y.; Endo, Y. Terahertz absorption spectra of fatty acids and their analogues. $J$. Oleo Sci. 60, 339-343(2011).

15) Upadhya, P. C.; Shen, Y. C.; Davies, A. G.; Linfield, E. H. Terahertz time-domain spectroscopy of glucose and uric acid. J. Biol. Phys. 29, 117-121(2003).

16) Saito, S.; Inerbaev, T. M.; Mizuseki, H.; Igarashi, N.; Note, R.; Kawazoe, Y. Terahertz phonon modes of an intermolecular network of hydrogen bonds in an anhydrous $\beta$-D-glucopyranose crystal. Chem. Phys. Lett. 423, 439-444 (2006).

17) Yu, B.; Zeng, F.; Yang, Y.; Xing, Q.; Chechin, A.; Xin, X.; Zeylikovich, I.; Alfano, R. R. Torsional vibrational modes of tryptophan studied by terahertz time-domain spectroscopy. Biophys. J. 86, 1649-1654(2002).

18) Yamamoto, K.; Tominaga, K.; Sasakawa, H.; Tamura, A.; Murakami, H.; Ohtake, H.; Sarukura, N. Terahertz time-domain spectroscopy of amino acids and polypeptides. Biophys. J. 89, L22-L26 (2005).

19) Korter, T. M.; Balu, R.; Campbell, M. B.; Beard, M. C.; Gregurick, S. K.; Heilweil, E. J. Terahertz spectroscopy of solid serine and cysteine. Chem. Phys. Lett. 418, 65-70 (2006).

20) Kutteruf, M. R.; Brown, C. M.; Iwaki, L. K.; Campbell, M. B.; Korter, T. M.; Heiweil, E. J. Terahertz spectroscopy of short-chain polypeptides. Chem. Physics. Lett. 375, 337-343 (2003).

21) Ohta S.; Yugi E.; The Theory and Practice of Fried Foods, Saiwai-Shobo, Tokyo, pp.144-145(1976).

22) Hu, Y.; Wang, X. H.; Guo, L. T.; Zhang, C. L.; Liu, H. B.; Zhang, X.C. Absorption and dispersion of vegetable oil and animal fat in THz range, Acta Physica Sinica 54, 4124-4128(2005). 